\title{
In situ temperature measurements through i-anvils \\ in diamond anvil cells
}

\author{
C. Gondé $^{1,2}$, H. Bureau ${ }^{1,3^{*}}$, M. Burchard ${ }^{4}$, S. Henry ${ }^{5}$, G. Simon ${ }^{1,3}$, J. Meijer ${ }^{6}$, S. Kubsky ${ }^{7}$ \\ ${ }^{1}$ Laboratoire Pierre Sue, UMR 9956 CEA-CNRS, CEA Saclay, 91191 Gif/Yvette, France \\ ${ }^{2}$ Institut des Sciences de la Terre d’Orléans, UMR 6113 CNRS-INSU Université d’Orléans \\ Université F. Rabelais Tours, Campus Géosciences, Bâtiment ISTO, 1a bis rue de la \\ Férollerie, 45071 Orléans cedex 2, France \\ ${ }^{3}$ Institut de Minéralogie et de Physique des Milieux Condensés, UMR CNRS 7590, Campus \\ Boucicaut, Bat 7, 140 rue de Lourmel, 75015 Paris, France \\ 4 Ruprecht-Karls Universität Heidelberg, Mineralogisches Institut, 69120 Heidelberg, \\ Germany \\ ${ }^{5}$ Laboratoire CSNSM, Bâtiment 108, 91405 Orsay Campus, France \\ ${ }^{6}$ RUBION, Ruhr Universität Bochum, 44780 Bochum, Germany \\ ${ }^{7}$ Laboratoire de Surfaces, Synchrotron Soleil, Saint-Aubin, France
}

\begin{abstract}
This study is devoted to in situ temperature measurement in diamond anvil cells (DAC) with implanted anvils (i-anvils). I-anvils consist of diamonds implanted with B and/or C ions, situated below the diamond's surface at a depth of 1-3 $\mu \mathrm{m}$; forming sensors which are placed below the culet at the location of the DAC's sample chamber. I-anvils can be employed as temperature or pressure sensors, exploiting their electrical properties. We have tested the sensor's behaviour with temperatures up to $900^{\circ} \mathrm{C}$, at ambient pressure and up to $6 \mathrm{GPa}$ in real
\end{abstract}


experimental conditions in two types of DAC. For this purpose, we performed experiments in four different i-anvils at temperatures up to $900^{\circ} \mathrm{C}$. We have compared the signal measured by the sensors with the temperature measured by a thermocouple attached to the i-anvil. The temperature gradient between the sample chamber and the thermocouple position was taken into account by phase transition measurements of calibration standards. Reproducible laws of current variation with temperature have been established. We conclude that i-anvils are reliable and sensitive to measure the temperature in situ in diamond anvil cells with an accuracy of better than $1^{\circ} \mathrm{C}$.

*corresponding author helene.bureau@impmc.jussieu.fr 


\section{Introduction}

In order to understand physical and chemical processes occurring in materials at pressure (P) and temperature $(\mathrm{T})$, different approaches have been developed over the past decades in Earth sciences and condensed matter physics. The understanding of natural processes requires studies under real conditions; therefore new experimental methods have to be developed. The principle is to realize equilibrium conditions at pressure and temperature in the laboratory, in order to reproduce and access physical and chemical conditions of the studied processes in atmospheres or the interiors of planets. In this last case, experimentation is the only way to observe and characterize inaccessible processes occurring at $\mathrm{P}$ and $\mathrm{T}$ far from room conditions (RC). Since the middle of the $20^{\text {th }}$ century, a number of devices have been developed to realize high pressure and high temperature experiments in two directions: either to study quench products at $\mathrm{RC}$ after equilibrium at $\mathrm{P}$ and $\mathrm{T}$ has been achieved; or to study the equilibrium in situ. Diamond anvils cells ${ }^{1-3}$ (DAC) are probably the most powerful tools in experimentation thanks to the use of diamonds as anvils because (1) they cover a large range of pressures, from a few MPa to few hundreds of GPa, and temperatures from $-180^{\circ} \mathrm{C}$ to a few thousands of ${ }^{\circ} \mathrm{C}$, from the interior of planets up to their surfaces; (2) they permit direct observation of the processes through the transparent diamonds in real time, free of any quench effects; (3) in situ characterization at pressure and temperature during experiments is possible through various spectroscopical techniques (X-rays, FTIR, Raman...). However, the success of such investigations relies on the exact determination of the parameters of the experiments: pressure $^{4-6}$ and temperature.

Depending on the $\mathrm{T}$ domain of investigation, different methods have been developed. The most commonly used is the measurement through two thermocouples (K-type within the range -180 to $1200^{\circ} \mathrm{C}$ ), usually glued on the mid-slope of each diamond anvil ${ }^{7}$. As the thermal conductivity of the diamond is very high, $\mathrm{T}$ is assumed to be homogeneous for the whole 
anvil. The advantage of employing a thermocouple is the accuracy $\left(<1^{\circ} \mathrm{C}\right)$, and the fact that it is not necessary to add temperature gauges in the sample chamber, which may interact with the sample during experiments. However, there are some disadvantages. As the measurement is not performed in the sample chamber of the DAC, there is a gradient between the position of the thermocouple (mid-slope) and the culet of the diamond. Therefore, $\mathrm{T}$ must be calibrated, assuming that the gradient is constant or linear. This is usually performed at room pressure through the observation of phase transitions of calibration standards, selected to cover a wide range of temperature. The thermal gradient is measured and corrected for by a linear relation. It is assumed to be also valid at pressures different from room pressure in the sample chamber. However, thermocouples may move and detach from the anvils during experiments. Rapid and repeated $\mathrm{T}$ cycles can weaken the thermal contacts used for $\mathrm{T}$ measurements. Then, the calibration is no longer valid and the temperature of the experiment may differ from the measurement. Additionally the thermal conductivity at the material boundaries (e.g. diamond/tungsten carbide WC seat) is a direct function of pressure. The best way to perform reliable $\mathrm{T}$ measurements during an experiment would be to place a $\mathrm{T}$ sensor in the sample chamber, in contact with the sample. This is possible through i-anvils ${ }^{8-10}$. The principle is based on the semiconducting properties of diamond known since the sixties ${ }^{11}$, and applied to industry ${ }^{12}$. When a diamond is doped with nitrogen $(\mathrm{N})$ or boron $(\mathrm{B})$, it increases the semiconducting properties. Recently, the implantation technique has been improved giving better control over the electronic properties of these devices ${ }^{13,14}$. Since 2000, this technique has been applied to diamond anvils in order to create electronic sensors sensitive to pressure and temperature during experiments performed in diamond anvil cells ${ }^{8,9}$. The aim of this study is to demonstrate the advances in the use of i-anvils as temperature sensors during diamond anvil cell experiments. 


\section{Experimental}

\subsection{Sensors principle and preparation}

The principle of the $\mathrm{T}$ sensor is to create a p-i-p (positive-intrinsic-positive) structure, below the diamond culet, with ohmic properties sensitive to temperature and pressure. Once the sensor has been implanted into the diamond structure and properly connected to the electrical measurement device, a constant potential of 0.1 to $10 \mathrm{~V}$ is applied between two contacts of the sensor. The applied potential gives rise to a current which can be expressed as a resistivity signal. This signal is modified by the temperature and/or pressure applied on the sensor.

The physical mechanisms involved during this process are detailed in Zaitsev et al. ${ }^{9}$, Vogel et al. ${ }^{14}$, Prins ${ }^{15}$ and will not be developed in the present study.

To realize the sensors, the p-i-p structure is implanted 1-2 $\mu \mathrm{m}$ below the surface of the culet of the diamond ${ }^{9,10}$. The structure consists of two successive implantations of crossed boron lines (p-layers) at two different beam energies, corresponding to different implantation depths, followed by a carbon (C) implantation below the sample chamber position (Fig. 1). This last implantation creates the intrinsic zone and connects the crossed lines electrically by an amorphous carbon region.

To connect the p-i-p structure to the measurement system, the B lines are connected to the surface of the anvil by a room temperature B implantation. These contact areas at the midslope of the anvil are graphitized and permit ohmic contacts to be made. A vacuum annealing step at $1500^{\circ} \mathrm{C}$ repairs the diamond lattice where possible and activates the $\mathrm{B}$ dopants. This annealing induces parasitic surface conductivity of the diamond. A cleaning step is necessary, either by acid attack or by $\mathrm{O}_{2}$ plasma leaching, to remove the electrical conductivity of the diamond surface.

Diamonds with a standard design (culets with 8 faces) are used. They are bevelled to protect the implanted structure from possible "chip outs" induced by the metallic gaskets on the 
corners and edges of the culets during DAC experiments. The final external connections are realized by applying a Platinum $(\mathrm{Pt})$ paste to the graphitized contacts, followed by a final annealing step. The so formed contacts are believed to be ohmic contacts ${ }^{13,15}$.

For this study, four sensors were implanted in four IA-type diamonds. B implantations were performed at RUBION, Ruhr Universität Bochum (Germany) and at the ARAMIS, CSNSM, Orsay (France) accelerators. Micro-implantation of C was performed at the RUBION ion projector $^{16}$. I-anvils preparation parameters are detailed in Table I.

\subsection{Diamond Anvil Cells}

We used two different types of diamond anvil cells. The first one is the Burchard-Zaitsev cell, described in Burchard et al. ${ }^{17}$ (Fig. 2). This cell has been especially developed for the use of ianvils, where the maximum obtainable pressure and temperature are $4 \mathrm{GPa}$ and $1100^{\circ} \mathrm{C}$ respectively. The body of the cell is equipped with a water cooling system and a reducing gas circulation system to avoid oxidation of diamonds, furnaces and contacts. The initial setup was slightly modified by adding Mo furnaces wrapped around the WC seats for external heating of the anvils. Connections are insured by a system of 8 WC needles applied to the B contacts on the mid-slope through steel springs [Fig. 2(b)]. The needles are used to fix and align the diamonds on their WC seats, and to provide contacts for the electrical measurements. In this DAC, the K-thermocouples are attached to the mid-slope of the anvils with steel springs, yielding a good reliability of the T measurements.

The second DAC used in the present study was recently designed and built for i-anvils ${ }^{18}$. It is inspired by the Burchard-Zaitsev DAC ${ }^{19}$ for the cell body, by the Bassett $\mathrm{DAC}^{7}$ for the external heating system and by the Chervin DAC for the pressure membrane ${ }^{3}$. The keyadvantage of this DAC is that pressures up to 40 GPa may be routinely reached thanks to the 
pressure membrane. In this new DAC, the diamonds are glued onto the WC seats with cement. A new connection system has been developed: thin and flexible Pt wires are connected to the i-anvils on the Pt contacts with a Pt paste protected by cement. Kthermocouples are glued onto the i-anvil to read-out the sample chamber temperature. For the pressure measurements, we have used the fluorescence lines of ruby spheres ${ }^{4}$.

\subsection{Experimental setup}

I-anvils are connected to a source meter/pico-ammeter allowing measurements of low currents through the DAC. A constant bias potential of $0.1 \mathrm{~V}$ to $10 \mathrm{~V}$ is applied to the sensor via two of

the 4 contacts, and the current across the sensor is measured (Fig. 3). The applied potential and the measured current could also be used to express the sensor response in terms of resistivity $(\mathrm{R}=\mathrm{V} / \mathrm{I})$. In our configuration, one single contact is used to attach the thermocouple. Connections are described with an equivalent resistivity diagram [Fig. 3(c)]. We have measured the A1B1, A1B2, A2B1, A2B2 connections through the p-i-p structure [Fig. 3(a)] and the A1A2, B1B2 connections [Fig. 3(b)] through one B lines. For each electrical measurement, a stabilization time of 10 to 15 min has been found to be necessary, the overall relative precision of intensity values is better than $10 \%$. The temperature measured with the K-thermocouple that is attached to the $\mathrm{i}$-anvil is compared to the electrical characteristics (resistivity or intensity) of the T sensor.

\section{Results}

\subsection{Room temperature characterization of the sensors}

Electrical properties of the sensors (resistivity $\mathrm{R}$, in $\mathrm{k} \Omega$ or intensity in $\mu \mathrm{A}$ ) are measured at RC for two different bias voltages in the DAC after a few minutes (Table I). We observe that 
the bias value does not change the resistivity at ambient temperature, and neither does the polarity (A1B1 versus B1A1). However, it is more accurate for the current (or resistivity) measurements to input a higher bias: therefore our measurements are performed with an input bias of 10 Volts. No significant changes were noticed between an opened and closed DAC. The influence of the introduction of a reducing gas in the cells' body $\left(\mathrm{Ar}-2 \% \mathrm{H}_{2}\right)$ resulted in a slight increase of the resistivity but this is insignificant compared to the measurement uncertainty. The influence of water cooling was noticed in the measurements, evidencing the high sensitivity of the sensors to temperature changes.

\subsection{Temperature measurements at room pressure}

Before performing measurements through the sensors, the exact temperature of the sample chamber should be known. Therefore, an absolute $\mathrm{T}$ calibration is performed by observing known phase transitions of calibration standards at room pressure: the melting points of $\mathrm{S}_{2}$ $\left(112.8^{\circ} \mathrm{C}\right), \mathrm{NaNO}_{3}\left(306.8^{\circ} \mathrm{C}\right), \mathrm{CsCl}\left(645^{\circ} \mathrm{C}\right)$ and $\mathrm{NaCl}\left(801^{\circ} \mathrm{C}\right)$. A complete temperature calibration was realized for Di6 (Fig. 4). The data can be fitted by linear regression (slope = 1.0062) indicating a small temperature gradient. Once the calibration of the K-thermocouple has been performed against these melting points, we can relate the electrical measurements through the sensor to the real temperature of the sample chamber.

Different cycles of I (current) measurements as a function of temperature for the sensors Di2 and Di6 have been carried out. We realized current measurements through the p-i-p structure, because it corresponds to measurements performed through the i-anvil culet's sensor that is nearest to the sample chamber. Figure 5 evidences the good reproducibility of the variation of I with temperature for a same pair of contacts, in a defined T range. Each anvil was found to exhibit an individual behaviour. 
Our measurements show that the measured current as a function of temperature $\mathrm{I}(\mathrm{T})$ can be described by:

$$
I(T)=I_{1} e^{-\frac{E_{1}}{k T}}+I_{2} e^{-\frac{E_{2}}{k T}}
$$

Equation 1

Where $\mathrm{k}$ is the Boltzmann constant $\left(\mathrm{eV} \mathrm{K}^{-1}\right)$, $\mathrm{T}$ the temperature $(\mathrm{K})$, and $\left\{\mathrm{I}_{1}, \mathrm{E}_{1}\right\}$ and $\left\{\mathrm{I}_{2}, \mathrm{E}_{2}\right\}$ are the fit parameters in $\Omega^{-1}$ and $\mathrm{eV}$ respectively.

The measured data cover the interval from RT (room temperature) to about $900^{\circ} \mathrm{C}$. Here we consider two exponential terms, describing the electronic situation in the $\mathrm{i}$-anvil ${ }^{8}$ by attributing activation energies ( $E_{1}$ and $E_{2}$ ). According to Wilson ${ }^{20}$, we assume that the conduction mechanism for low temperatures (up to about $400^{\circ} \mathrm{C}$ ) can be attributed to defect conduction or Mott-hopping (nearest neighbour hopping, $\mathrm{NNH}$ ), as the activation energies for this mechanism are in the range of $\mathrm{kT}$ at $\mathrm{RT}(=0.026 \mathrm{eV})$. In this region, the temperature changes the mobility of defect-induced carriers.

For higher temperatures however, the conduction is dominated by activated carriers, acceptors from $\mathrm{B}$ and donors from $\mathrm{N}$. We suggest that the reason for the very different absolute values of the conductivity of our diamonds and their integrated sensors may result from the crosscompensation of $\mathrm{B}$ dopants by the locally varying $\mathrm{N}$ concentration, inducing local charge zones. This is especially true for the type IA used in the present study, known to contain $\mathrm{N}$ (up to $0.1 \mathrm{wt} \%$ ). This explains why our values for $\mathrm{E}_{2}$ are neither corresponding exactly to the activation energy of $\mathrm{B}(=0.37 \mathrm{eV})$, nor to that of $\mathrm{N}(=1.7 \mathrm{eV})$, but are mostly in between this values. In this region, the temperature acts primarily on carrier concentration. A more detailed explanation of the electronic mechanisms involved is still under discussion. 
In practice, this parameterisation of the data delivers very accurate fits, with fit parameters as listed in Table II. The resulting fits are found to be close to the experimental data, within a relative error of $\pm 5 \%$.

For the experiments performed in the Burchard-Zaitsev DAC (Di2 and Di3), we observed that the $\mathrm{T}$ calibration is very sensitive to disconnections of the anvils from the cell body, when the diamonds are connected through WC needles: when the cell configuration is changed between two cycles of measurements, two distinct laws of I variation were determined [Fig. 6(a)], especially for $\mathrm{T}>300^{\circ} \mathrm{C}$. We also observed by optical microscopy that connections through WC needles mechanically damage the external contacts of the diamonds by removing the Pt of the contacts. This may be the reason of the changes of sensor response. Finally, we observed during experiments that the anvils should be protected from any oxidation or degassing events (i.e. Molybdenum Mo, [Fig. 6(b)]) from the furnaces if the gas circulation is stopped. Such events modify the surface conductivity and/or cover the Pt contacts, isolating them from the WC needles. For the diamond Di6, which was connected with Pt wires, even after one wire has been broken and replaced, the values of the contacts were reproducible.

\subsection{Pressure measurements at two selected temperatures}

Two series of pressure-dependent measures have been carried out at fixed $\mathrm{T}, \mathrm{RT}$ and $100^{\circ} \mathrm{C}$, respectively (Fig. 7). The diamond (Di1) was connected with Pt flexible wires in the pressure membrane DAC. The two series have been recorded during decompression with the same protocol as described above. We observe a fourfold higher sensitivity at $100^{\circ} \mathrm{C}$ with respect to RT. The measurements show a continuously rising behavior. Detailed analysis of the physical processes as well as a broader pressure range will be explored in a forthcoming manuscript. 


\section{Discussion}

We have tested four sensors implanted in four IA diamonds set up in DAC in real experimental conditions. Our results show that it is possible and reliable to measure the temperature in the sample chamber by using the resistivity or current intensity response of the sensor to a given applied potential.

We observed that the relation of temperature measured through a thermocouple versus current intensity is reproducible for successive heating stages (Fig. 5). We determined that each sensor exhibits specific electrical properties and that it is important to establish current variation laws for the range of temperatures needed for any further experiments.

A sensor's response is different depending on the connection chosen between two of the four possibilities through the p-i-p structure. As the intensity of the signal increases with the temperature (resistivity decreases with temperature), it is required to choose the connection with the higher starting resistivity to realize more accurate measurements. We have established that the sensors are very sensitive to T: we found a maximum change of $166 \mu \mathrm{A}$ for a $1^{\circ} \mathrm{C}$ variation [Fig. 5(a)]. Fig. 8 shows the current change versus temperature for a p-i-p structure implanted in a IIA diamond ${ }^{9}$ for two different bias voltages. We observed a similar behaviour of the sensor with respect to $\mathrm{T}$ than for the three IA diamonds of the present study: I variation laws as a function of $\mathrm{T}$ are of exponential-type (see Equation 1, Table II). In Fig. 8, the bias voltage input is different and we see that it has an influence on I response with T. The higher the bias voltage, the more accurate are the I variation measurements. The measured relative intensity values are reproducible within $\pm 10 \%$ for all measured diamonds up to $450^{\circ} \mathrm{C}$ during temperature cycling.

Zaitsev et $a l^{9}$ have proposed an accuracy of $0.01^{\circ} \mathrm{C}$ for the measurement of I through the p-i-p structure. However, in their measurements, a Pt foil was placed between the two anvils in a 
Burchard-Zaitsev DAC, with no sample chamber. The presence of a hole in the gasket may alter the sensor's response. A metallic layer placed between the two diamonds insures perfect thermal conductivity. In real DAC experimental conditions, the sample chamber causes a thermal gradient between the two anvils. This may partly explain why we found an accuracy of about $1^{\circ} \mathrm{C}$.

We have observed that any change in the configuration of the experiment can change the sensor response drastically. The sensors are very fragile and should be protected from any oxidation process. In the Burchard-Zaitsev DAC, the WC needles connection system has been demonstrated to damage the external contacts of the diamonds by removing the Pt, leading to calibration modification when the diamond is dismantled from the DAC, whereas the connections through flexible Pt wires are more reliable.

Vogel et al. ${ }^{14}$ have studied the mechanical stability of the $\mathrm{T}$ sensors and the electronic properties of the B lines with temperature. They show that implanted B lines are not affected by heating cycles.

A comparison of the measurements performed along a B line and through the p-i-p diode shows similar response to $\mathrm{T}$ changes. Whereas the $\mathrm{p}-\mathrm{i}-\mathrm{p}$ structure has been created to be more sensitive to pressure compared to a single implanted B line or two crossed distinct B lines ${ }^{9}$, it has the advantage to offer a smaller sensor area $\left(70 \times 70 \mu \mathrm{m}^{2}\right)$. This area is in touch with the sample through the amorphous diamond layer on top of the p-i-p structure, whereas measurements through a single B line reflect the temperature of the diamond bulk.

We have shown in Fig. 7 that temperature sensors are reliable also at elevated pressures of up to at least $6 \mathrm{GPa}$ and give an exploitable signal.

The influence of pressure on the $\mathrm{T}$ sensor has to be determined. Actually, the use of sensors for pressure measurements is more difficult because the sensors are very sensitive to the 
variation of temperature: a $\Delta \mathrm{T}$ of $1^{\circ} \mathrm{C}$ would correspond to a $\Delta \mathrm{P}$ of $0.1 \mathrm{GPa}^{9}$. The sensor is so sensitive to temperature that the dissociation of the two signals is problematic. However, the data presented in fig 7 suggest that this dissociation is possible. Calibrations by using known phase transitions with respect to $\mathrm{P}$ and $\mathrm{T}$, or in situ X-Ray diffraction measurements on pure materials such as gold ${ }^{21}$ in the studied $\mathrm{P}, \mathrm{T}$ range should provide very accurate $\mathrm{T}$ calibration. Maybe the final $\mathrm{C}$ implantation at the cross of the B lines is not necessary to use the sensor as a $\mathrm{T}$ sensor, as it would diminish the sensitivity of the sensor with respect to pressure. Further studies are necessary to answer this question.

Temperature determination through intensity measurements of implanted sensors is less difficult and even more accurate and reliable than K-thermocouple readout. The measurement spot is closer to the sample, and at a constant position below the sample chamber, protected by the diamond network. Sensor response has been demonstrated to be not affected by in situ X-ray spectroscopy or diffraction in the $\mathrm{DAC}^{19}$ or by in situ Raman spectroscopy.

\section{Conclusions and perspectives}

In conclusion, we have demonstrated that sensors implanted in the diamond structure of diamond anvils, “i-anvils”, are reliable, reproducible and accurate temperature sensors. The experimental conditions presently investigated cover up to $900^{\circ} \mathrm{C}$ and up to $5 \mathrm{GPa}$. They can be routinely used during diamond anvil cells experiments after having been properly calibrated either with observation of phase transitions or by using in situ measurements such as X-ray diffraction on pure materials. We have shown that the sensors should be connected to the measurement devices (source meter pico-ammeter) with flexible Pt wires. This connection system is more reliable but should be improved in the future. The pressure effect on the $\mathrm{T}$ reading through sensors can be taken into account with a priori calibration 
performed at the $\mathrm{P}$ and $\mathrm{T}$ conditions of the experiment. The decoupling of the signal due to pressure versus the signal due to temperature signal in the p-i-p sensor will be the challenge of our future studies.

\section{Acknowledgements}

We thank Stéphane Lequien for his support during the course of this research, Jean-Claude Chervin, Pascal Munsch, Gilles Lemarchant, François Nicolas for their precious assistance. We are grateful to the ARAMIS, Orsay and RUBION, Bochum staffs during diamond implantations. Many thanks to James Ablett for English improvements of the manuscript. The collaboration between Germany and the implantations at the RUBION accelerator were possible thanks to the PROCOPE PAI 11316XK (H. Bureau-M. Burchard) and to the French High-Pressure technology Network’s (reseauHP). The first author's PhD thesis was funded by the French CEA. The whole project was funded with the ANR-JC05-42281 program (Fluide in situ- H. Bureau).

\section{References}

${ }^{1}$ C.E. Weir, E.R. Lippincott, A. Van Valkenburg, E.N. Bunting, J. Res. Nat. Bur. Stds (US) 63A, 55 (1959)

${ }^{2}$ H.K. Mao, J. Xu, P.M. Bell, Geophys. Res. B91, 4673 (1986)

${ }^{3}$ J.C. Chervin, B. Canny, J.M. Besson, P. Pruzan, Rev. Sci. Instr. 66, 2595 (1995)

${ }^{4}$ J.C. Chervin, B. Canny, N. Mancinelli, High Press. Res. 21,305 (2002)

${ }^{5}$ F. Datchi, B. Canny, Phys. Rev. B69, 144106 (2004) 
${ }^{6}$ C. Sanchez-Valle, I. Martinez, I. Daniel, P. Philippot, S. Bohic, A. Simionovici, Am. Mineral. 88, 978 (2003)

${ }^{7}$ W.A. Bassett, A.H. Shen, M. Buckunm, I.M. Chou, Rev. Sci. Instrum. 64, 2340 (1993)

${ }^{8}$ A.M. Zaitsev, A.V. Denisenko, A.A. Melnikov, V.S. Varichenko, G. Kosaca, B. Burchard, J. Von Borany, M. Werner, W.R. Fahrner, J. Wide Bandgap Mat. 7, 4 (1999)

${ }^{9}$ A.M. Zaitsev, M. Burchard, J. Meijer, A. Stephan, B. Burchard, W.R. Fahrner, W.V. Maresch, Phys. Stat. Sol. A185, 59 (2001)

${ }^{10}$ H. Bureau, M. Burchard, S. Kubsky, S. Henry, C. Gondé, A. Zaistev, J. Meijer, High Press. Res. 26, 251 (2006)

${ }^{11}$ V.S. Vavilov, V.B. Stopachinskii, V.S. Chanbarisov, Sov. Phys. Solid State 8, 2126 (1966)

${ }^{12}$ J.F. Prins, Phys. Rev. B39, 3764 (1989)

${ }^{13}$ J.F. Prins, Phys. Res. B35, 484 (1988)

${ }^{14}$ T. Vogel, J. Meijer, A.M. Zaistev, Diam. Rel. Mat. 13, 1822 (2004)

${ }^{15}$ J.F. Prins, Semicond. Sci. Technology 18, S27 (2003)

${ }^{16}$ J. Meijer, A. Stephan, Microelec. Ing. 41-42, 257 (1998)

${ }^{17}$ M. Burchard, A.M. Zaistev, W.V. Maresch, Rev. Sci. Instrum. 74, 1263 (2003)

${ }^{18}$ P. Munsch, H. Bureau, B. Couzinet, A. Somogyi, E. Foy, G. Simon, S. Kubsky, J.C. Chervin, in : Les verrous technologiques de l'expérimentation haute pression. Réseau de technologie des hautes pressions, CNRS Editions, 187 (2009)

${ }^{19}$ M. Burchard, S. Kubsky, H. Bureau, A. Somogyi, V. Malavergne, B. Menez, M. Munoz, High Press. Res. 26, 235 (2006)

${ }^{20}$ W.B. Wilson, Phys. Rev. 127, 1549 (1962)

${ }^{21}$ D.L. Heinz, R. Jeanloz, J. Appl. Phys. 55, 885 (1984) 
TABLE I - Sensors description

\begin{tabular}{|c|c|c|c|c|c|}
\hline & & Di1 & Di2 & Di3 & Di6 \\
\hline \multirow[t]{6}{*}{$\begin{array}{l}\text { Sensor } \\
\text { preparation }\end{array}$} & $\begin{array}{l}\text { B lines }\left(\text { at.cm }{ }^{-2}\right) \\
850^{\circ} \mathrm{C}\end{array}$ & $\begin{array}{l}1 \mathrm{MeV}: 2 \cdot 10^{16} \\
2 \mathrm{MeV}: 2 \cdot 10^{16}\end{array}$ & $\begin{array}{l}1 \mathrm{MeV}: 2.10^{16} \\
2 \mathrm{MeV}: 2.10^{16}\end{array}$ & $\begin{array}{l}1 \mathrm{MeV}: 2.10^{16} \\
2 \mathrm{MeV}: 2.10^{16}\end{array}$ & $\begin{array}{l}1 \mathrm{MeV}: 2.10^{16} \\
2 \mathrm{MeV}: 2.10^{16}\end{array}$ \\
\hline & $\begin{array}{l}\text { B contacts }\left(\text { at.cm }{ }^{-2}\right) \\
\text { ambient } T\end{array}$ & $2 \mathrm{MeV}: 2.10^{16}$ & $2 \mathrm{MeV}: 2.10^{16}$ & $2 \mathrm{MeV}: 2.10^{16}$ & $2 \mathrm{MeV}: 2.10^{16}$ \\
\hline & C stripe (at.cm ${ }^{-2}$ ) & $5 \mathrm{MeV}: 10^{18}$ & $5 \mathrm{MeV}: 10^{18}$ & $5 \mathrm{MeV}: 10^{18}$ & $5 \mathrm{MeV}: 10^{18}$ \\
\hline & Leaching & Acid attack & Acid attack & Acid attack & $\mathrm{O} 2$ plasma \\
\hline & Surface resistivity (M $\Omega$ ) & $\sim 10$ & $\sim 10$ & $\sim 18$ & $>20$ \\
\hline & Connexion in DAC & Flexible Pt wires & WC needles & WC needles & Flexible Pt wires \\
\hline \multirow{9}{*}{$\begin{array}{l}\text { Electrical } \\
\text { characteristics } \\
\text { ambient T }\end{array}$} & $\begin{array}{l}\text { Resistivity }(\mathrm{k} \Omega) / \\
\text { intensity }(\mu \mathrm{A})\end{array}$ & source $10 \mathrm{~V}$ & source $0.1 \mathrm{~V}$ & source $0.1 \mathrm{~V}$ & source $10 \mathrm{~V}$ \\
\hline & B line & & & & \\
\hline & $\mathrm{A} 1 \mathrm{~A} 2$ & $7,26 / 1377$ & $72 / 1.4$ & $56 / 1.8$ & $5220 / 1.9$ \\
\hline & B1B2 & $2170 / 4.6$ & $35 / 2.9$ & $97 / 1.0$ & $897 / 11.1$ \\
\hline & p-i-p diode & & & & \\
\hline & A1B1 & $2180 / 4.6$ & $36 / 2.8$ & $81 / 1.2$ & $632 / 15.8$ \\
\hline & A1B2 & 13,95 / 716 & $2176 / 0.05$ & $96 / 1.0$ & $530 / 18.9$ \\
\hline & A2B1 & 2170 / 4.6 & $55 / 1.8$ & $45 / 2.2$ & $5560 / 1.8$ \\
\hline & A2B2 & 10,44 / 957 & 498 / 0.2 & $66 / 1.5$ & $5490 / 1.8$ \\
\hline
\end{tabular}




\section{TABLE II - Fit parameters of the I parameterization as a function of $\mathrm{T}$.}

In italic, fit parameters which relative errors are superior to 50\%. For Di2, and for connection A1B2-1, the term 2 is negligible for temperature less than $1400^{\circ} \mathrm{C}$.

\begin{tabular}{llllll}
\hline Diamond & Connections & \multicolumn{2}{l}{ Fit Parameters } \\
& & Term 1 & & Term 2 & \\
& & $\mathbf{I}_{\mathbf{1}}$ & $\mathbf{E}_{\mathbf{1}}$ & $\mathbf{I}_{\mathbf{2}}$ & $\mathbf{E}_{\mathbf{2}}$ \\
& & $\mathbf{\Omega}^{-\mathbf{1}}$ & $\mathbf{e V}$ & $\mathbf{\Omega}^{-\mathbf{1}}$ & $\mathbf{e V}$ \\
\hline Di2 & A2B1-1 & 0,000051 & 0,026 & 0,00063 & 0,33 \\
& A2B1-2 & 0,00052 & 0,027 & 0,00051 & 0,22 \\
& A2B2-1 & 0,00019 & 0,11 & 1053,5 & 1,17 \\
& A1B2-1 & 0,000017 & 0,09 & 0,011 & 2,099 \\
& A1B2-2 & 0,000065 & 0,127 & 13,48 & 0,76 \\
\hline Di3 & A1B1-1 & 0,000062 & 0,0398 & 0,00098 & 0,1732 \\
& A1B1-2 & 0,00029 & 0,082 & 963,14 & 1,06 \\
\hline Di6 & A1B1-1 & 0,000011 & 0,06 & 0,0148 & 0,633 \\
& A1B1-2 & 0,000012 & 0,056 & 0,06 & 0,74 \\
\hline Zaitsev (2001) & 0,1 V & 0,000043 & 0,054 & 0,00049 & 0,26 \\
& 1 V & 0,000129 & 0,022 & 0,00077 & 0,206 \\
\hline
\end{tabular}

\section{Captions}

FIG. 1 - Schematic view (a) and picture (b) of an implanted diamond. The two B implanted lines are represented in (1) and (2), the C implanted line in (3). The external B contacts areas are at the mid-slope of the diamond (4).

FIG. 2 - Image (a) of the Burchard-Zaistev diamond anvil cell and schematic view of the connection system (b). The implanted diamond (Id) is placed on its WC seat. Two needles (2) are touching the A1 and A2 contacts, linked to the steel springs (1) and wires (3), directly to the cell body (4). 
FIG. 3 - Schematic view of resistivity and temperature measurements (Th = thermocouple) of i-diamond through p-i-p structure (a), via one B line (b) and equivalent circuit diagram of resistivity (c) measured on exterior contacts (from Burchard et al. ${ }^{19}$ ).

FIG. 4 - Calibration curve of the temperature in the sample chamber of the DAC by using melting points of $\mathrm{NaNO}_{3}\left(306.8^{\circ} \mathrm{C}\right), \mathrm{CsCl}\left(645^{\circ} \mathrm{C}\right)$ and $\mathrm{NaCl}\left(801^{\circ} \mathrm{C}\right)$.

FIG. 5 - Variation of I with temperature for i-anvil Di2 (a) and Di6 (b).

For Di2, $\{\star, \diamond\}$ corresponds to A2B1 connections (cycle 1, cycle 2); $\left\{{ }^{+}, \boldsymbol{\bigcirc}\right\}$ corresponds to A2B2 connections (cycle 1, after heating); $\{\times, \square\}$ corresponds to A1B2 connections (cycle 1, cycle 2). For Di6, $\{\times, \square\}$ corresponds to A1B1 connections (cycle 1, cycle 2).

Successive measurements of intensity were performed through the p-i-p structure. For each pair of connections, exponential laws (Equation 1) are determined to express $\mathrm{T}\left({ }^{\circ} \mathrm{C}\right)$ as a function of I $(\mu \mathrm{A})$. Fit parameters are described in Table II. For temperatures up to about $700^{\circ} \mathrm{C}$, the second term in Equation 1 is negligible compared to the first term (for A1B2-1 connection of Di2, this second term is negligible up to $1400^{\circ} \mathrm{C}$ ). We observe that all measurements are reproducible for one pair of connections.

FIG. 6 - Variation of I with temperature for i-anvil Di2 (a) and Di3 (b).

For Di2, $\{\times, \square\}$ corresponds to A1B2 connections (cycle 1, after dismantling). For Di3, $\{\star, \square\}$ corresponds to A1B1 connections (cycle 1, cycle 2).

In (a), the variation of I for Di2 is measured through A1B2 contacts via p-i-p structure. Two cycles of measurements are made at an interval of one day, with a change in the cell configuration. The two variations laws are exponential-type (see Table II)

In (b), a probably Mo degassing occurred during the experiment. 
FIG. 7 - Variations of I with pressure at room temperature $\{\bigcirc\}$ and at $100^{\circ} \mathrm{C}\{\square\}$ for i-anvil Di1 during decompression cycles. I was measured through p-i-p structure. More details will be provided in a coming publication.

FIG. 8 - Variation laws of I in a i-anvil for IIA-type diamond (after Zaistev et al. ${ }^{9}$ ) for two bias voltages compared to a variation law of current in a i-anvil for IA-type diamond (this study). $\{+, \square\}$ corresponds to IIA-type diamond, bias voltage of $0,1 \mathrm{~V}$ and $1 \mathrm{~V}$ respectively; corresponds to IA-type diamond, bias voltage $10 \mathrm{~V}$.

The three laws are exponential-type (see Table II). Increasing bias voltage seems to enhance the accuracy of the current variation with temperature. 


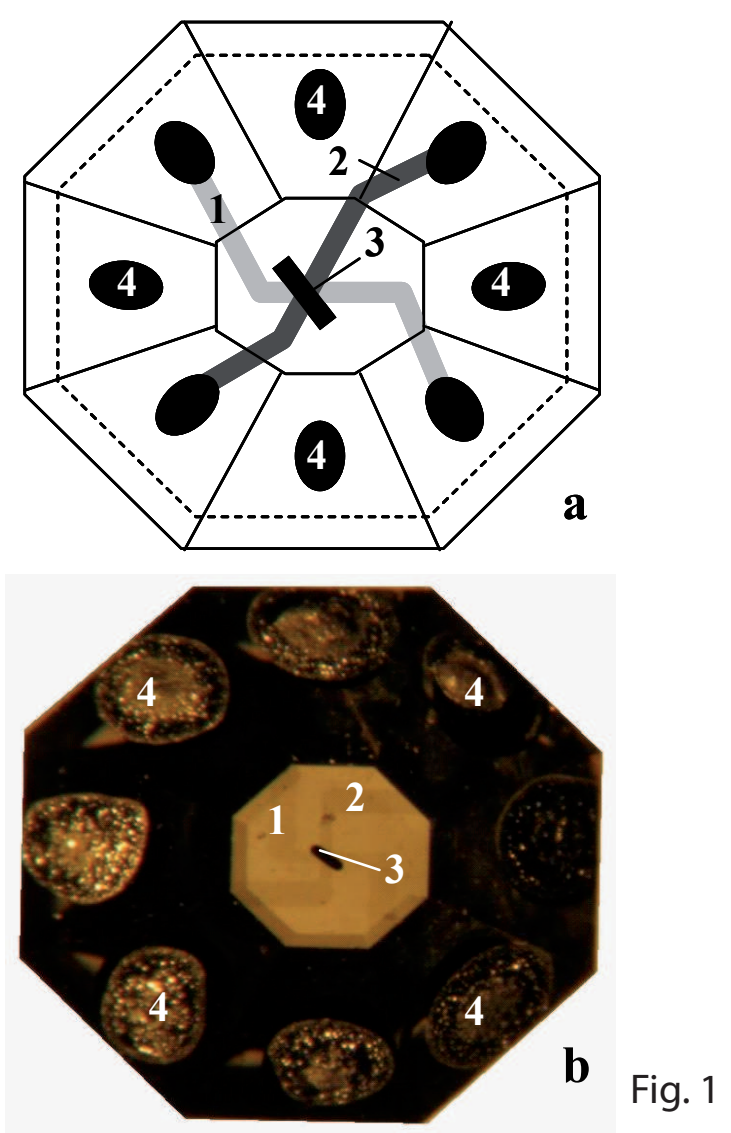



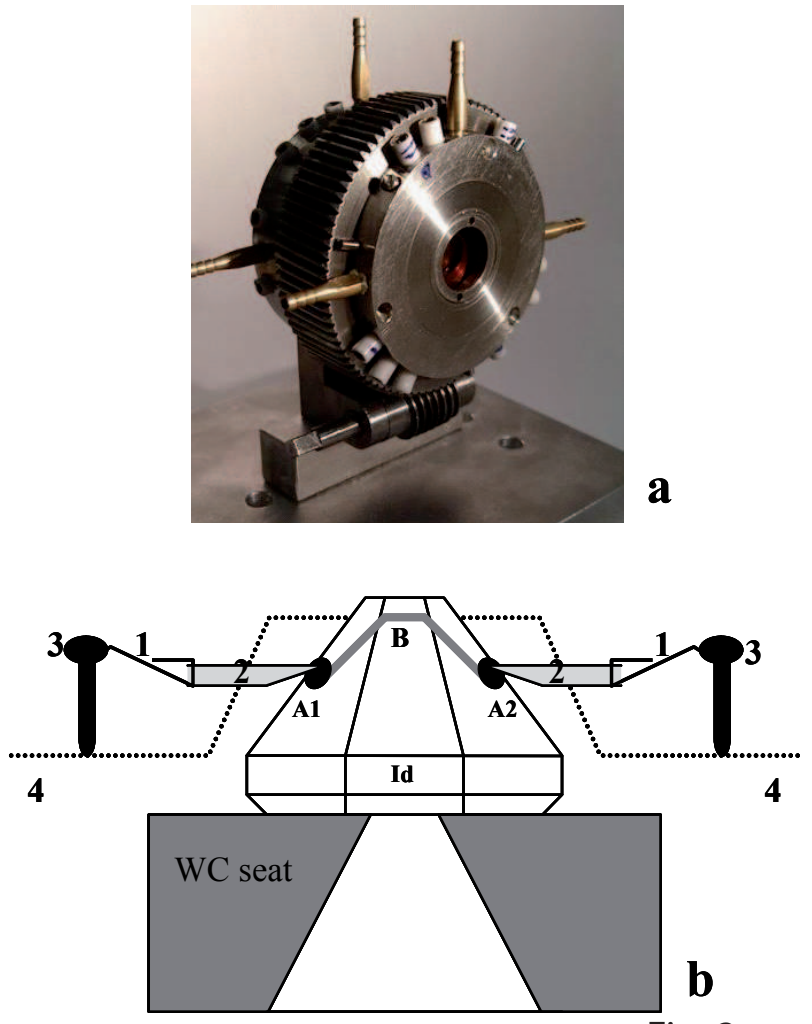

Fig. 2 

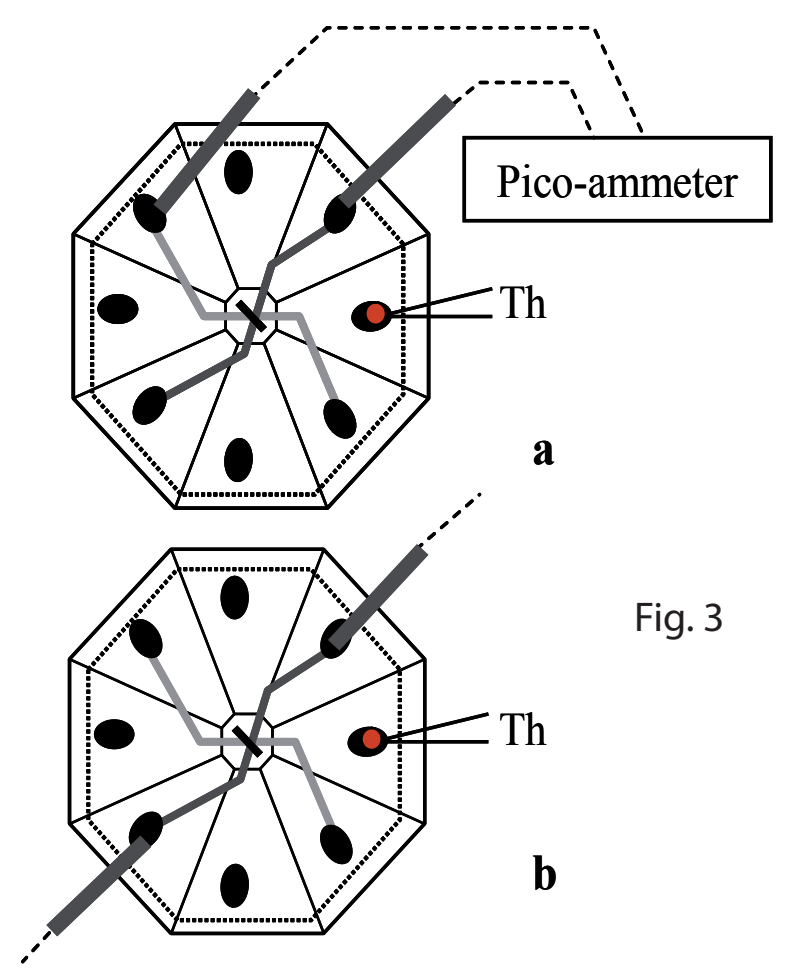

Fig. 3

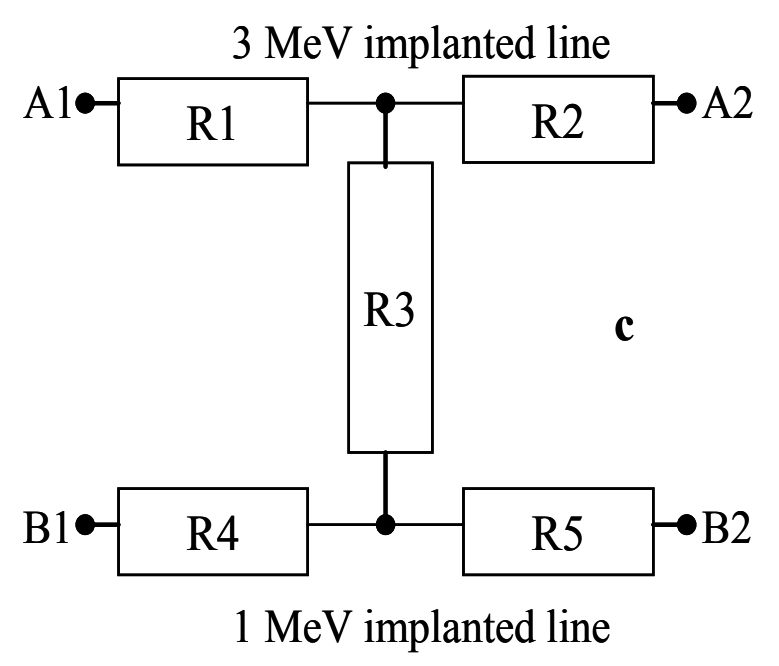




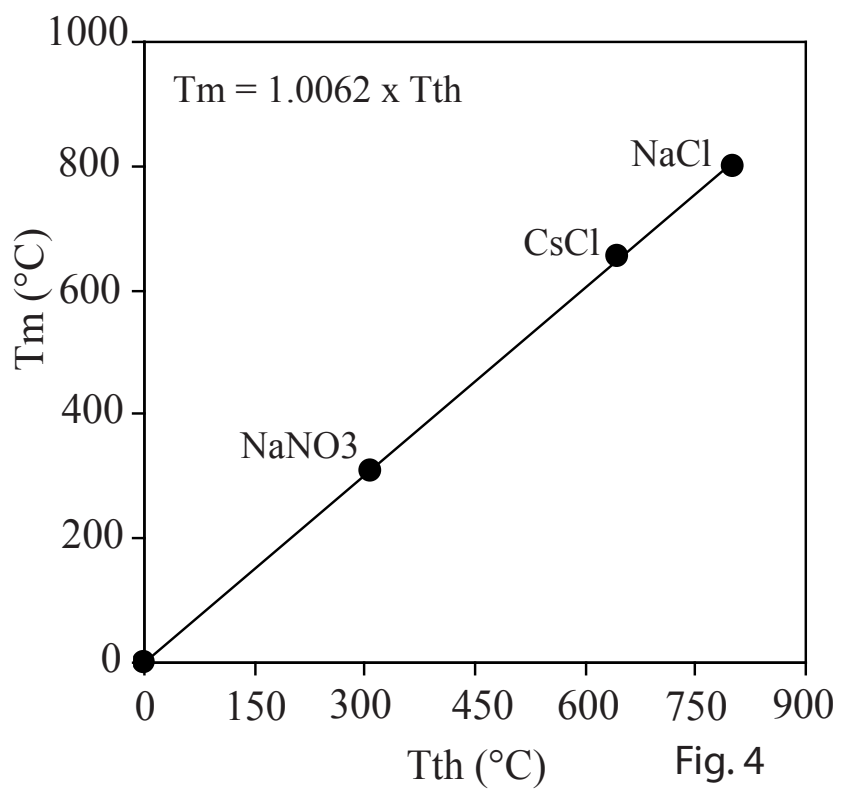



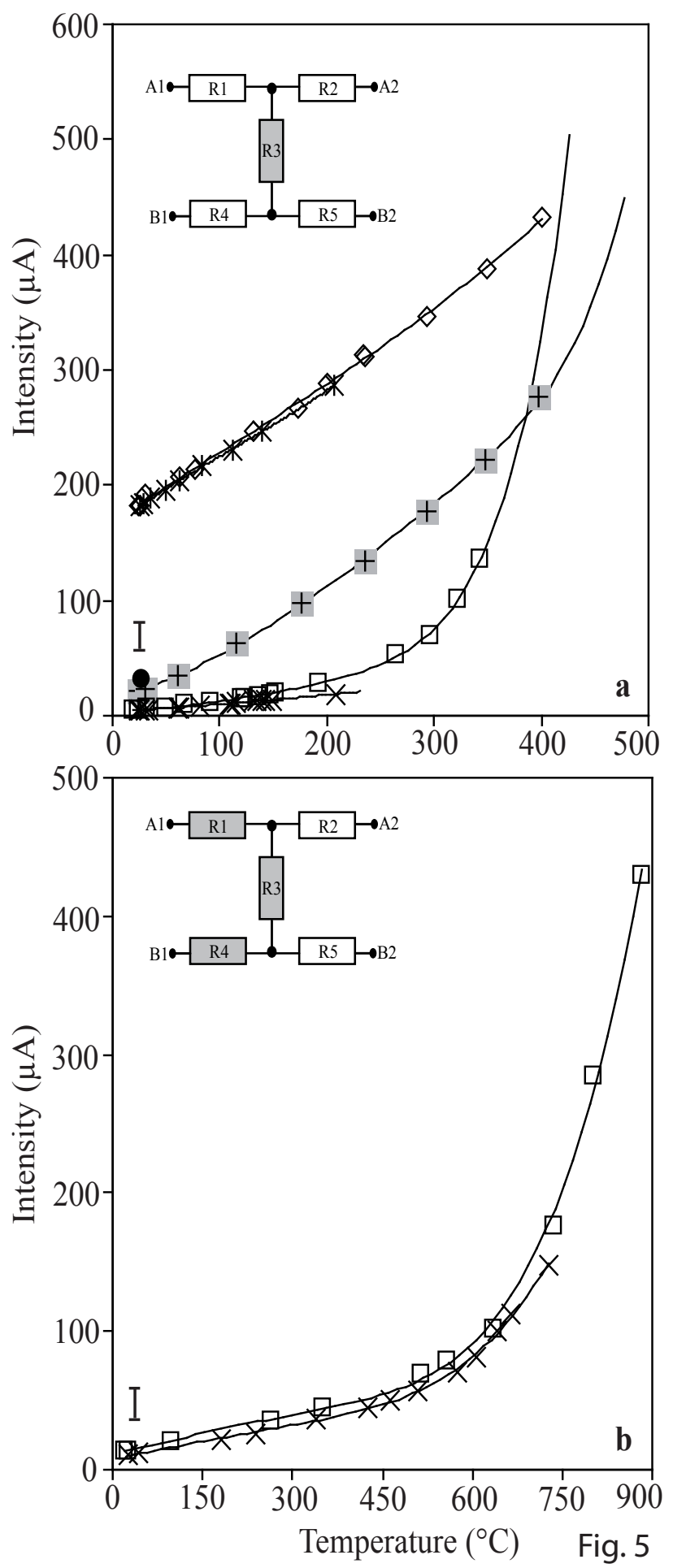

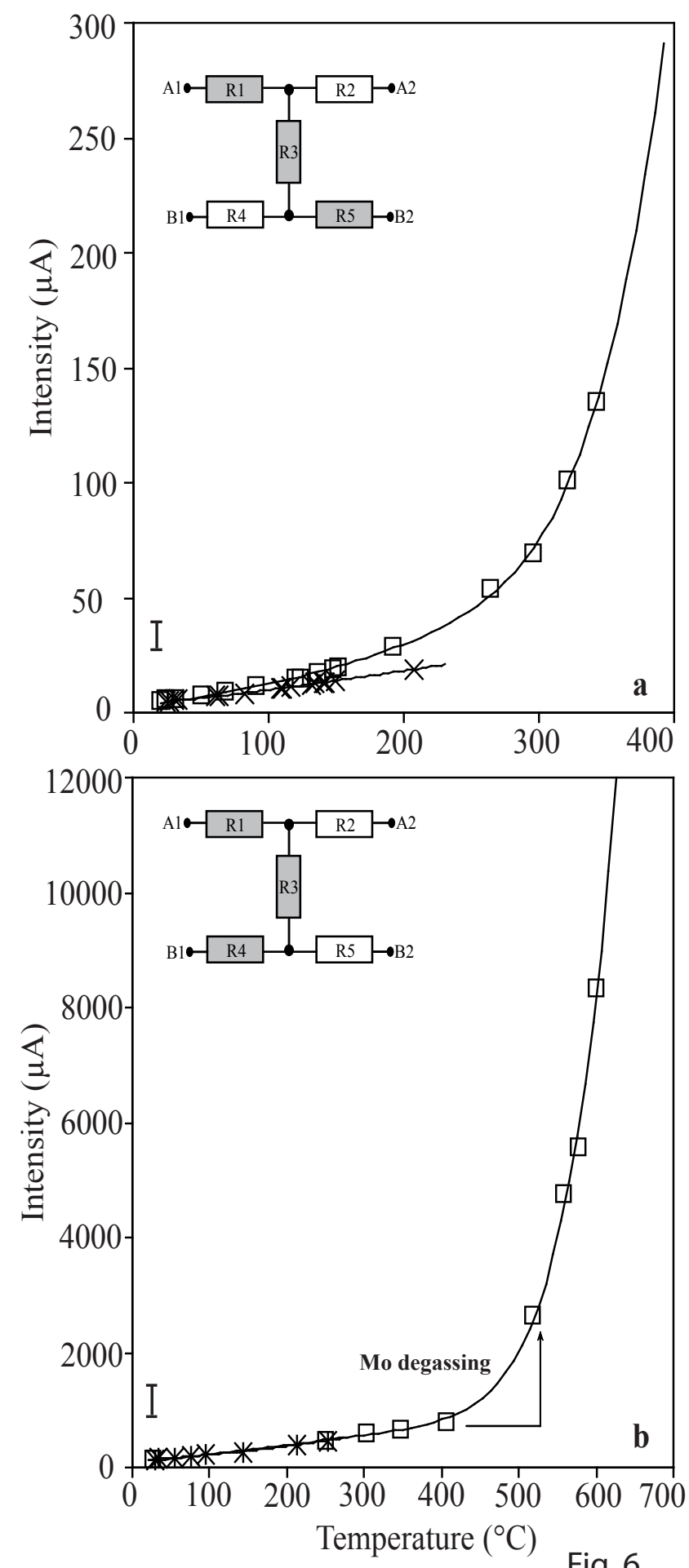

Fig. 6 


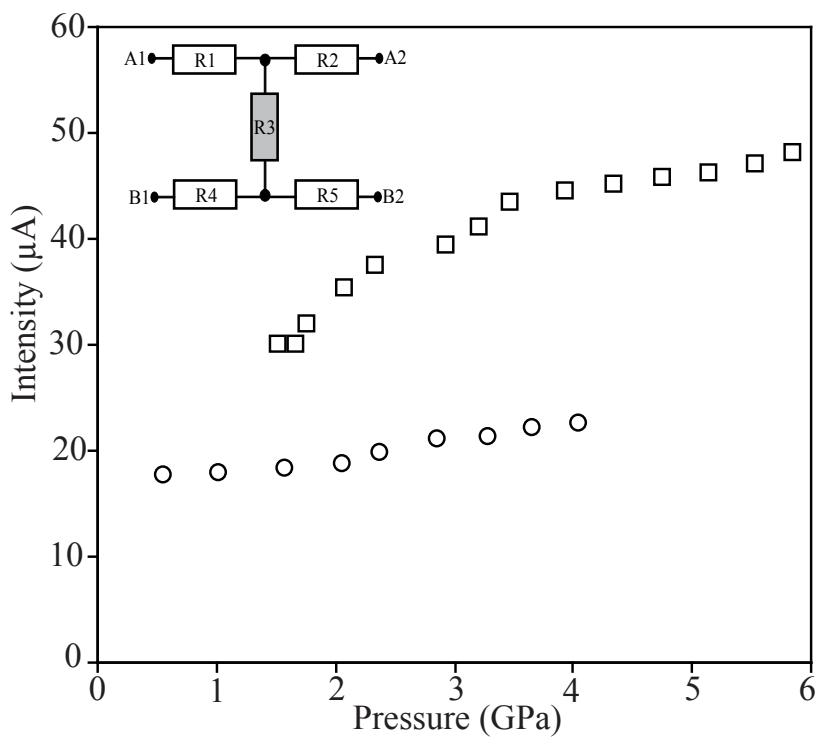

Fig. 7 


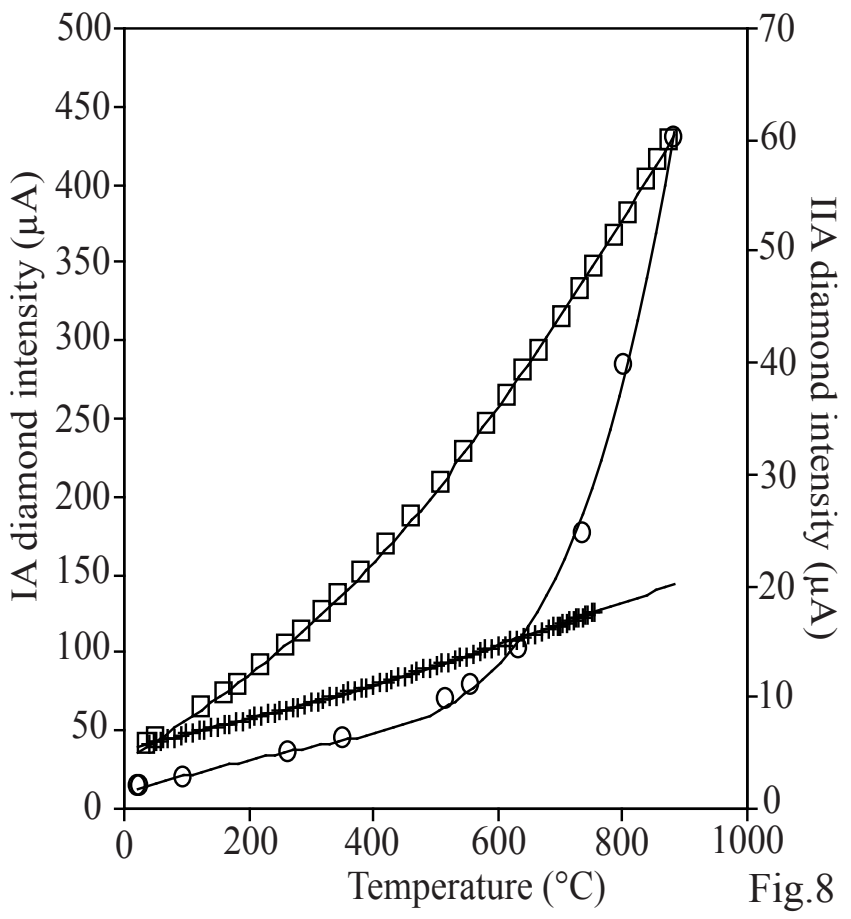

